Bakgrunn: Smerter hos barn er undervurdert og underbehandlet. Internasjonalt rapporteres sykepleieres holdninger og manglende kunnskaper som viktige årsaker til mangelfull smertebehandling.

Hensikt: $\AA$ kartlegge norske sykepleieres og spesialsykepleieres kunnskaper om og holdninger til smerter hos barn og ungdom i alderen 0-18 år innlagt på sykehus.

Metode: Studien er en tverrsnittsstudie med kvantitativ tilnærming. Den norske versjonen av kartleg- gingsverktøyet Pediatric Nurses' Knowledge and Attitudes Survey Regarding Pain (PNKAS-N) er benyttet. Skjemaet består av 40 spørsmål som omhandler smertehåndtering, smertevurdering, bruk av medikamentell og ikke-medikamentell smertelindring. Studien inkluderte 238 sykepleiere og spesialsykepleiere ved åtte barneavdelinger og en høyskole.

Resultater: Det endelige utvalget består av 183 deltakere som gir en svarprosent på 76,9 prosent. Sykepleierne svarte riktig på 71,2 prosent av spørsmålene. Spesialsy- kepleierne skåret signifikant bedre enn sykepleierne $(p<0,001)$.

Konklusjon: Både sykepleierne og spesialsykepleierne hadde et godt teoretisk kunnskapsnivå. Studien avdekker imidlertid et gap mellom den kunnskap sykepleierne og spesialsykepleierne hadde, og de vurderingene som ble gjort når de ble stilt overfor to pasienthistorier. En holdningsendring er nødvendig for at sykepleiere og spesialsykepleiere skal stole på pasientens egenvurdering av smerten og administrere tilstrekkelig mengde smertestillende medikamenter.
Background: Pain in children is underestimated and undertreated. Nurses' attitudes and lack of knowledge are internationally reported as major causes of insufficient treatment of pain.

Objective: To survey Norwegian paediatric nurses' knowledge and attitudes regarding pain in hospitalized children and adolescents (0-18 years).

Methods: This is a quantitative study with a cross-sectional design. The Norwegian version of Pediatric Nurses' Knowledge and Attitudes
Survey Regarding Pain (PNKAS-N) was used. The PNKAS-N consists of 40 items which address general pain management, pain assessment and the use of pharmacological and non-pharmacological treatment. The study included 238 nurses and nurse specialists at eight paediatric units and one university college.

Results: The final sample consists of 183 participants giving a response rate of $76.9 \%$. A total of $71.2 \%$ of the questions were correct answered. The nurse specialists scored significantly higher than the nurses $(p<0.001)$.
Conclusion: The nurses and nurse specialists have a high level of theoretical knowledge in several key areas. However, the study reveals a gap between their knowledge and how the nurses and nurse specialists actually manage pain, measured by two clinical cases. A change of attitudes seems necessary to make them trust the patients' own assessment of pain and to administer adequate amounts of analgesics.

Keywords; Paediatric Nursing, Pain, Pain Management, Pain Knowledge - Attitudes, Practice. 


\section{Norske sykepleieres kunnskap om og holdning til smerter hos barn}

Forfattere: Kari Raaum Hovde, Tone Høilo Granheim, Knut-Andreas Christophersen og Alfhild Dihle

\section{NøKKELORD}

- Smerte

- Barn

- Kunnskapsbasert sykepleie

\section{INTRODUKSJON}

Smerte regnes som en av de mest stressbetonte opplevelser i et menneskeliv (1). Utover opplevelsen i seg selv, har underbehandlet smerte negative konsekvenser som forverring av skade, forsinket sårtilheling, forlenget sykehusopphold (2) og utvikling av kroniske smerter $(2,3,4)$. Studier viser at barn opplever moderat og alvorlig grad av smerte under sykehusopphold (5-7) og at smerter verken vurderes eller behandles tilfredsstillende $(3,8$ 10). Dette står i kontrast til uttalelsen fra The American Academy of Pediatrics (AAP) og American Pain Society (APS) (2001) om at «most acute pain experienced in medical settings, can be prevented or substantially relieved» (9).

I «Yrkesetiske retningslinjer for sykepleiere» står det: «sykepleierens fundamentale plikt er å vise omsorg for alle som lider» (11). Smertelindring bør derfor være et av sykepleiernes hovedanliggender. Fagkunnskaper og gode holdninger er avgjørende for å lindre smerte. Til tross for at det de siste årene er publisert mye om barn og smerte (12), rap- porteres sykepleieres holdninger og manglende kunnskaper som viktige årsaker til utilfredsstillende smertelindring (13). Frykt for overmedisinering, frykt for tilvenning til opioider og engstelse for respirasjonsdepresjon, er noen av områdene det eksisterer mangelfulle kunnskaper innenfor $(8,14-17)$. Studier fra Finland og Sverige viser at sykepleiere trenger mer kunnskap om farmakologisk og ikke-farmakologisk smertehåndtering $(18,19)$. Videre vurderes og dokumenteres smerte mangelfullt i praksis (20) og myter, som at barn ikke føler smerte på samme måte som voksne, eksisterer fortsatt (8). Funnene fra en norsk studie viser at leger, sykepleiere og barnepleiere vurderte egen kunnskap som mangelfull, og at utilstrekkelig smertevurdering og mangelfull ordinasjon av medikamenter var barrierer for effektiv smertebehandling av nyfødte (21).

Hensikten med studien var å beskrive sykepleiere og spesialsykepleieres kunnskaper om og holdninger til smerter hos barn og ungdom i alderen 0-18 år, innlagt på sykehus. En slik studie er ikke gjennomført i Norge tidligere, da ingen validerte kartleggingsverktøy har vært tilgjengelig på norsk.

\section{METODE}

\section{Utvalg}

I denne tverrsnittsundersøkelsen ble alle 209 sykepleiere og spesialsykepleiere ved fire medisinske avdelinger, to kirurgiske avdelinger og to intensivavdelinger fra tre universitetssykehus i Helse Sør-Øst inviterte til å delta. I tillegg ble to kull med i alt 29 sykepleiere i videreutdanning innen barnesykepleie ved en høyskole invitert til å delta. I alt ble 238 sykepleiere, sykepleiere i videreutdanning og spesialsykepleiere invitert. Siden flere av spørsmålene i spørreskjemaet omhandler bruk av opioider, foregikk rekrutteringen på barneavdelinger hvor det er vanlig å administrere opioider. Avdelinger som behandler både barn og voksne ble ekskludert.

\section{Hva tilfører artikkelen?}

Artikkelen viser at det er et gap mellom den kunnskapen sykepleiere har om smerter hos barn og vurderinger de gjør i praksis.

\section{Mer om forfatterne:}

Kari Raaum Hovde er MSN, RN og barnesykepleier ved Oslo Universitetssykehus, Ullevål. Tone Høilo Granheim er MSN, RN og sykepleier ved Akershus Universitetssykehus, HF, Gastrokirurgisk avdeling. Knut-Andreas Christophersen er MSc og universitetslektor i statistikk ved Universitetet i Oslo, Det samfunnsvitenskapelige Fakultet. Alfhild Dihle er PhD, CRNA, RN, 1.-amanuensis og dr.philos. ved Diakonhjemmet Høgskole, Avdeling for Sykepleie. Kontakt: uxkavdaous-hf.no 


\section{Instrumenter}

Vi brukte den norske versjonen av spørreskjemaet Pediatric Nurses' Knowledge and Attitudes Survey Regarding Pain (PNKAS-N), fordi det inneholder spørsmål knyttet til flere av områdene hvor kunnskapsmangel påpekes $(16,22)$. PNKAS(-N) bygger på anerkjente standarder for smertehåndtering utgitt av World Health Organization (WHO), APS og The Agency for Health Care Policy and Research (AHCPR) (15). PNKAS ble utviklet fra et spørreskjema som er rettet mot voksne pasienter kalt «The Nurses' Knowledge and Attitudes Survey Regarding Pain (NKAS) (22). Begge skjemaene baseres på følgende definisjon administrere riktig mengde morfin til ungdommene. PNKAS-N har fem spørsmål som retter seg spesielt mot ungdom, ett spørsmål er kun relevant $\mathrm{i}$ forhold til spedbarn, mens de øvrige spørsmålene er aktuelle for alle barn i alderen 0-18 år. Et eget skjema ble benyttet for å innhente informasjon om bakgrunnsvariablene alder, utdanning, arbeidserfaring og stillingsbrøk.

\section{Datainnsamlingen}

Datainnsamlingen ble utført i perioden desember 2008 til februar 2009. Rekruttering foregikk via ledelsen ved den enkelte barneavdeling og høyskole. Muntlig informasjon om prosjektet ble gitt på personalmøter og $\mathrm{i}$

\section{Sykepleiere har ansvar for å vurdere pasientens smerter.}

av smerte; "Pain is whatever the experiencing person says it is, existing whenever he says it does» (23).

Oversettelsen av PNKAS til norsk fulgte internasjonale retningslinjer $(24,25)$ og er vurdert med hensyn til reliabilitet og validitet (26). PNKAS-N består av 40 spørsmål innenfor områdene; smertehåndtering og smertevurdering, samt bruk av medikamentell og ikke-medikamentell smertelindring. I de første 23 spørsmålene skal det tas stilling til om et utsagn er sant eller usant. Videre er det 13 multiple choice-spørsmål som har fra tre til seks svaralternativer hvor kun ett svaralternativ er riktig. De fire siste spørsmålene tar utgangspunkt $\mathrm{i}$ to pasienthistorier hvor sykepleierne skal smertevurdere to ungdommer som angir sin smerteintensitet på en skala fra 0 til 10. I tillegg skal sykepleierne en klassetime. De som ikke deltok der fikk spørreskjemaet og et informasjonsskriv i sin posthylle. Besvarelsene ble lagt i en merket boks plassert på hver avdeling. Purring ble gjort to ganger via avdelingens ledelse. På høyskolen var ikke purring nødvendig, fordi skjemaene ble fylt ut av dem som ønsket å delta på ett bestemt tidspunkt uten andre til stede enn studentene selv.

\section{Etiske overveielser}

Etiske retningslinjer ble fulgt (27). Studien ble godkjent av Personvernombudet for forskning hos Norsk Samfunnsvitenskapelige Datatjeneste (NSD). Dette inkluderte et informasjonsskriv der studiens konfidensialitet og frivillige deltakelse ble understreket. Nødvendige tillatelser ble innhentet fra skjemaets forfattere, det enkelte sykehus, samt høyskole. For å ivareta deltakernes anonymitet og for å imøtekomme instrukser fra ett av sykehusene ble alder delt inn i seks kategorier, mens kjønn ikke ble registrert.

\section{Statistiske analyser}

Dataene er analysert ved bruk av SPSS versjon 17. Deskriptiv statistikk er benyttet for å analysere bakgrunnsdata. Utvalget ble delt i to; en gruppe med sykepleiere og en gruppe med spesialsykepleiere. Videreutdanningsstudentene som nettopp hadde startet på sin utdanning ( $\mathrm{N}=15)$ ble slått sammen med sykepleiergruppen. Studentene i kullet som hadde fjorten dager igjen av studiet $(\mathrm{N}=14)$ ble slått sammen med spesialsykepleiergruppen. Sumskår er det samme som antall korrekte svar for hvert enkelt skjema. Sumskår ble gjennomsnittsberegnet i begge grupper. Forskjell i gjennomsnittlig sumskår mellom sykepleiere og spesialsykepleiere ble undersøkt med students t-test. Signifikansnivået ble satt til 5 prosent $(\mathrm{p}<$ $0,05)$. Videre ble det beregnet prosentvise korrekte svar på hvert av de 40 spørsmålene både i det samlede utvalget og i hver av de to gruppene.

\section{RESULTATER}

\section{Bakgrunnsvariabler}

Totalt 183 (76,9 prosent) besvarte spørreskjemaet, fordelt på 79 sykepleiere og 104 spesialsykepleiere. Av de 183 som besvarte spørreskjemaet er det flest i aldersgruppen 30-39 år. Nesten alle $i$ utvalget har en stillingsprosent fra 75 til 100. De fleste spesialsykepleierne er utdannet barnesykepleiere. Spesialsykepleierne har nesten tre ganger så lang arbeidserfaring som sykepleierne. Oversikt over alder, utdanningsnivå, stillingsbrøk og arbeidserfaring fremkommer av tabell 1 . 


\section{Resultater fra spørreundersøkelsen}

Det er mulig å oppnå 40 poeng på spørreskjemaet. I denne spørreundersøkelsen varierte oppnådd poengsum mellom 14 og 39 med et gjennomsnitt på 28,5 poeng $(71,2$ prosent) i hele utvalget. Spesialsykepleierne skåret i gjennomsnitt 30 poeng (75 prosent), mens sykepleierne skåret 26,5 poeng $(66,3$ prosent), se tabell 2 . Resultatet fra t-testen viste at det er statistisk signifikant forskjell i sumskår mellom sykepleiere og spesialsykepleiere, $\mathrm{t}=5,77, \mathrm{p}<0,001$.

Mellom 91,7 prosent og 100 prosent av det samlede utvalget svarer riktig på de ti mest korrekt besvarte spørsmålene. Tabell 3 gir en oversikt over hvilke spørsmål dette omhandler.

Det spørsmålet som sjeldnest ble besvart korrekt var knyttet til følgende pasientsituasjon. Korrekt svar er markert med uthevet skrift.

Andreas er 15 år gammel, og dette er hans første dag etter operasjonen. Idet du kommer inn på rommet, smiler han til deg og fortsetter å snakke og spøke med den som er på besøk. Dine observasjoner viser følgende; $B T=120 / 80$, hjertefrekvens $=80$, respirasjonsfrekvens $=18$. På en skala fra $0-10$ (hvor $0=$ ingen smerte eller ubehag, $10=$ verst tenkelige smerte/ubehag), angir han sin smerte til 8 .

I pasientens kurve skal du markere hans grad av smerter på skalen under. Sett kryss i den boksen du mener representerer din vurdering av Andreas' smerter:

\section{\begin{tabular}{llllllll|l|ll}
0 & 1 & 2 & 3 & 4 & 5 & 6 & 7 & 8 & 9 & 10
\end{tabular}}

Legens ordinasjon av smertestillende medikament er «Morfin 1-3 mg IV ved behov inntil hver time til smertelinding».

Hvilket tiltak vil du iverksette op dette tidspunktet?

= Gi 3 mg Morfin IV nå.
TABELL 1: Demografiske data ( $N=183)$.

\begin{tabular}{|c|c|c|}
\hline Karakteristika & $\%$ & (N) \\
\hline \multicolumn{3}{|l|}{ Alder } \\
\hline $20-29$ & 32,2 & (59) \\
\hline $30-39$ & 41,0 & (75) \\
\hline $40-49$ & 14,2 & (26) \\
\hline $50-59$ & 9,3 & (17) \\
\hline Missing & 3,3 & (6) \\
\hline \multicolumn{3}{|l|}{ Utdanningsnivå } \\
\hline Bachelor grad & 43,2 & (79) \\
\hline Master grad/PhD & 0,0 & (0) \\
\hline Spesialutdanning & 56,8 & (104) \\
\hline \multicolumn{3}{|l|}{ Gruppen med spesialutdanning $(\mathrm{N}=104)^{*}$} \\
\hline Barn & 58,5 & (62) \\
\hline Intensiv & 33,0 & (35) \\
\hline Anestesi & 8,5 & $(9 *)$ \\
\hline Total & 100 & $106^{*}$ \\
\hline \multicolumn{3}{|l|}{ Stillingsbrøk } \\
\hline $75-100 \%$ & 88,6 & (162) \\
\hline $50-74.9 \%$ & 10,4 & (19) \\
\hline$<50 \%$ & 0,5 & (1) \\
\hline Missing & 0,5 & (1) \\
\hline Arbeidserfaring (år) & Mean & (SD) \\
\hline Erfaring som sykepleier & 10,16 & $(8,03)$ \\
\hline Erfaring i sykepleie til barn & 8,22 & $(7,14)$ \\
\hline Erfaring ved nåværende avdeling & 6,12 & $(5,75)$ \\
\hline Kun sykepleiere med Bachelor grads erfaring & 5,76 & $(6,50)$ \\
\hline Kun spesialsykepleieres erfaring & 13,50 & $(7,48)$ \\
\hline
\end{tabular}

\section{Forkortelser: SD, standard avvik}

* To av spesialsykepleierne ( $N=104)$ hadde spesialutdanning både $\mathrm{i}$ intensiv sykepleie og i anestesisykepleie. I analysene ble disse 2 spesialsykepleierne tatt med i gruppen av intensiv sykepleiere.

TABELL 2: Oversikt over sykepleiernes gjennomsnittlige sumskår i poeng med prosent i parentes ( $N=183)$.

\begin{tabular}{lcccc}
\hline & N & Gj.snitt sumskår & St.avvik & Variasjon \\
Sykepleiere & 79 & $26,46(66,1 \%)$ & 3,9 & $17-36$ \\
Spesialsykepleiere & 104 & $30,04(75,1 \%)$ & 4,5 & $14-39$ \\
Barnesykepleiere & 62 & $30,60(76,5 \%)$ & 4,0 & $22-39$ \\
Andre spesialsykepleiere & 42 & $29,27(73,2 \%)$ & 5,0 & $14-39$ \\
\hline
\end{tabular}


TABELL 3: De ti best besvarte spørsmålene.

\begin{tabular}{|c|c|c|c|}
\hline Påstand. Rett svar står uthevet. & Totalt & $\begin{array}{l}\text { Spesial- } \\
\text { sykepl. }\end{array}$ & Sykepl. \\
\hline $\begin{array}{l}\text { Barnet/ ungdommen med smerter bør oppmun- } \\
\text { tres til å tåle så mye smerter som mulig før en } \\
\text { tyr til smertelindrende tiltak (usant). }\end{array}$ & $100 \%$ & $100 \%$ & $100 \%$ \\
\hline $\begin{array}{l}\text { Foreldre skal ikke være til stede under } \\
\text { smertefulle prosedyrer (usant). }\end{array}$ & $98,3 \%$ & $98,1 \%$ & $98,7 \%$ \\
\hline $\begin{array}{l}\text { Smertestillende medikamenter før kontinuer- } \\
\text { lige/ vedvarende smerter bør gis: } \\
\text { Til faste tider gjennom døgnet. }\end{array}$ & $97,2 \%$ & $95,1 \%$ & $100 \%$ \\
\hline $\begin{array}{l}\text { Etter at den første dosen med et opioid er gitt, } \\
\text { bør påfølgende doser justeres i samsvar med } \\
\text { den enkelte pasients respons (sant). }\end{array}$ & $96,7 \%$ & $100 \%$ & $92,4 \%$ \\
\hline $\begin{array}{l}\text { Barn/ ungdom bør vurderes individuelt for } \\
\text { å bestemme hvorvidt kulturell bakgrunn } \\
\text { påvirker deres smerteopplevelse (sant). }\end{array}$ & $95,6 \%$ & $97,1 \%$ & $93,6 \%$ \\
\hline $\begin{array}{l}\text { Den anbefalte administrasjonsmåten for opioi- } \\
\text { der til barn med kortvarige, sterke smerter med } \\
\text { akutt start, som ved traumer eller postoperative } \\
\text { smerter er: Intravenøst. }\end{array}$ & $95,6 \%$ & $100 \%$ & $89,9 \%$ \\
\hline $\begin{array}{l}\AA \text { A gi barn/ ungdom injeksjon med sterilt vann } \\
\text { (placebo) er ofte en nyttig test for å avgjøre om } \\
\text { smerten er reell (usant). }\end{array}$ & $92,8 \%$ & $98 \%$ & $85,9 \%$ \\
\hline $\begin{array}{l}\text { Spedbarn under } 6 \text { måneder tåler ikke } \\
\text { opioider som smertelindring (usant). }\end{array}$ & $92,1 \%$ & $100 \%$ & $81,8 \%$ \\
\hline $\begin{array}{l}\text { Barn under } 2 \text { år har nedsatt smertefølsom- } \\
\text { het og begrenset hukommelse for smertefulle } \\
\text { opplevelser, fordi nervesystemet deres ikke er } \\
\text { ferdig utviklet (usant). }\end{array}$ & $91,8 \%$ & $99 \%$ & $82,3 \%$ \\
\hline $\begin{array}{l}\text { Den mest sannsynlige forklaringen på hvorfor } \\
\text { et barn/en ungdom med smerter ber om økte } \\
\text { doser smertestillende medikamenter er: } \\
\text { Barnet /ungdommen opplever økte smerter. }\end{array}$ & $91,7 \%$ & $97,1 \%$ & $84,6 \%$ \\
\hline
\end{tabular}

Totalt 39,8 prosent av spesialsykepleierne og 26,9 prosent av sykepleierne besvarte korrekt at Andreas' smerteintensitet er lik 8 . De ble videre bedt om å vurdere hvilken dose morfin han behøver. Lege har forordnet 1-3 mg inntil hver time, inntil pasienten er smertelindret. Totalt 33,3 prosent av spesialsykepleierne og 15,4 prosent av sykepleierne ville gi maksimal dose med morfin på $3 \mathrm{mg}$ ut fra legens forordning i denne pasienthistorien. Av det samlede utvalget besvarte 18 prosent korrekt på begge spørsmålene og 21,9 prosent valgte ikke å gi noe morfin. Disse vurderte pasientens smerteintensitet i gjennomsnitt til å være 2,8 . I tabell nr. 4 vises en oversikt over de øvrige ni spørsmålene som er minst korrekt besvart.

\section{DISKUSJON}

Dette er den første studien som evaluerer sykepleieres og spesialsykepleieres kunnskaper om og holdninger til smerte hos barn $i$ et europeisk land ved bruk av
PNKAS. Utvalget i denne studien har tilnærmet samme prosent korrekte svar som studier i USA med bruk av PNKAS (15, 16). Hovedfunnene som fremkommer av studien er at både sykepleiere og spesialsykepleiere har gode kunnskaper på flere områder innen fagfeltet, men at det eksisterer et gap mellom teoretisk kunnskap og praktisk handling, synliggjort gjennom to pasienthistorier. Spørsmål knyttet til medikamenter, opioideavhengighet, faren for respirasjonsdepresjon ved bruk av opioider og overrapportering av smerter var blant de ti dårligst besvarte spørsmålene. Et positivt funn var at myten om at spedbarn ikke tåler opioider og ei heller kan huske smertefulle opplevelser er inne på listen over de ti best bevarte spørsmålene.

Nesten 90 prosent av det samlede utvalget mener at barnet/ungdommen selv er den som best kan bedømme egen grad av smerte, at smerte er «det pasienten sier at det er». Når deltakerne stilles overfor to pasienthistorier, nyttiggjøres imidlertid ikke denne kunnskapen tilfredsstillende. Om lag 2/3 mener at pasienten har mindre smerte enn han selv uttrykker, 8 på en skala fra $0-10$. Kun 25 prosent gir pasienten maksimal dose med morfin ut fra forordning. Dette til tross for at 100 prosent sier at barn ikke bør oppmuntres til å tåle smerte, og at smerte skal vurderes og behandles individuelt. Når deltakerne får opplyst at pasienten grimaserer og viser tegn på smerter, øker korrekt svarprosent. Likevel mener fortsatt cirka 30 prosent av spesialsykepleierne og nesten 40 prosent av sykepleierne at pasienten har mindre smerte enn han selv uttrykker. Det kan se ut som om sykepleierne og spesialsykepleiernes kunnskaper 
TABELL 4: De øvrige ni dårligst besvarte spørsmålene.

\section{Påstand. Rett svar står uthevet.}

Et barn med kontinuerlige / langvarige smerter har fått opioider daglig i 2 mnd. Dosene økte i denne perioden. I går fikk barnet morfin $20 \mathrm{mg} /$ time intravenøst. I dag har han fått $25 \mathrm{mg} /$ time intravenøst i 3 timer. Sannsynligheten for at barnet utvikler respirasjonsdepresjon av klinisk betydning er: Mindre enn $1 \%$.

Angstdempende, beroligende og sovemidler (barbiturater), er hensiktsmessige medikamenter for smertelindring ved smertefulle prosedyrer (usant).

Den anbefalte administrasjonsmåten for opioider til barn med kontinuerlige / vedvarende smerter, er: Peroralt.

\begin{abstract}
Avhengighet av narkotiske stoffer/opioider defineres som psykologisk avhengighet ifølge med en altoppslukende interesse for å skaffe og bruke narkotika. Ikke av medisinske årsaker. men for å oppnå en psykisk effekt. Det kan forekomme med eller uten fysiologisk toleranseutvikling og fysisk avhengighet (abstinens).

Med utgangspunkt i denne definisjonen, hvor sannsynlig er det at opioid avhengighet vil oppstå som et resultat av behandling med opioider? $<1 \%$.
\end{abstract}

Hvilken av de følgende intravenøse dosene med morfin tilsvarer $15 \mathrm{mg}$ morfin gitt peroralt?

5 mg morfin iv.

Hvilke av de følgende medikamentene er nyttige $i$ behandlingen av smerter hos barn? Alle tre medikamenter; Ibux, Morfin og Sarotex.

Hvilket av de følgende smertestillende medikamentene blir betraktet som førstevalg i behandlingen av langvarige moderate til sterke smerter hos barn? Morfin.

Spedbarn/barn/ungdom kan sove til tross for sterke smerter (sant).

Hvor stor prosentandel av pasientene tror du overrapporterer sin grad av smerte? 0/10 \%
Totalt

\section{$22,4 \% \quad 29.5 \% \quad 13,3 \%$}

Spesial-

$35,8 \% \quad 44,6 \% \quad 24,4 \%$

$36,7 \% \quad 42,6 \% \quad 29,1 \%$

$37,4 \% \quad 45,5 \% \quad 26,9 \%$ sykepl. Sykepl.

pasienter overrapporterer grad av smerter oftere enn det som er tilfelle.

Kirkevold (2002) skriver at både teoretisk kunnskap, praktisk kunnskap og etisk kunnskap må integreres i utøverens kompetanse for å innvirke på den enkeltes handlinger i møte med pasienten. Refleksjon og kritisk tenkning inngår som viktige komponenter (28). A gi smertestillende medikamenter vil ikke alltid ha en synlig, observerbar virkning. Smertelindring kan fort bli sykepleierens valg, i motsetning til andre typer behandling. Sykepleiere har ansvar for å vurdere pasientens smerter og administrere tilstrekkelig mengde forordnet analgetika. Dette er forankret i Helsepersonellovens $\mathbb{} 4$ med kravet til faglig forsvarlighet og å yte omsorgsfull hjelp (29). Sykepleiere kan være den som fremmer optimal smertelindring, eller være en barriere med økt lidelse for barnet som konsekvens (30). Vincent (2005) vurderte i sin studie mengde administrert analgetika opp mot mengde forordnet analgetika. Sykepleierne administrerte kun 37,9 prosent av den mengde morfin de hadde mulighet til å gi ut fra forordninger, samt 22,8 prosent av total mengde smertestillende medikamenter som var tilgjengelig ut fra forordninger (17). Jacob og Puntillo (31) beskriver at 60 prosent av sykepleierne ved en spørreundersøkelse mener at smertebedømming er nødvendig fra hver til hver annen time, mens de i praksissituasjoner kun dokumenterer dette i 10-15 prosent av tilfellene. Dette viser at det kan være et gap mellom det sykepleiere sier at de bør gjøre og hva de faktisk gjør i kliniske situasjoner. Dihle et al. (32) fant også dette i en norsk studie om postoperativ 
smertehåndtering av voksne pasienter. Sykepleiere hadde teoretisk kunnskap om sentrale temaer innen postoperativ smertehåndtering, men denne kunnskapen ble ikke tilstrekkelig anvendt i pasientsituasjoner. Sykepleieren kan dermed bli en barriere for god smertehåndtering.

Spørsmålene om respirasjonsdepresjon og medikamentavhengighet er blant de som oftest besvares feil. Dette stemmer med hva AAP (2004) tidligere har rapportert (8). Studier fra USA utført med PNKAS har også spørsmålene om respirasjonsdepresjon (15-17) og opio- spedbarn ikke tåler opioider. Smertebehandling av nyfødte var bortimot ikke eksisterende for noen tiår siden (33). Operasjoner ble gjennomført med minimalt med smertestillende medikamenter frem til 1987 (34) og ved prosedyresmerte fikk heller ikke denne pasientgruppen tilfredsstillende smertelindring (35). Viktig forskning utført på 1980- og 1990-tallet utfordret eksisterende myter og kunnskap innen feltet er forbedret. Utfordringen fremover blir å implementere gjeldende kunnskap i klinisk praksis (36).

Det er knyttet begrensninger

\section{Sykepleieren kan bli en barriere for god smertehåndtering.}

ideavhengighet (17) blant de ti som hyppigst besvares feil. Engstelse for at pasientene skal utvikle respirasjonsdepresjon og medikamentavhengighet kan derfor være noe av forklaringen på at det ikke gis maksimal mengde forordnet morfin til en pasient som bedømmer egen grad av smerte til 8 , på en skala fra 0-10. En annen forklaring kan være at nesten halvparten av studiens deltakere ikke vet at morfin betraktes som førstevalget i behandlingen av moderat til sterke smerter hos barn. Det kan også være, som i studien her, at mange sykepleiere ikke vurderer at pasienten har så sterke smerter som pasienten selv uttrykker.

Det er gledelig at hele 91,8 prosent av det samlede utvalget og 99 prosent av spesialsykepleierne ikke lenger tror på myten om at barn under to år har nedsatt smertefølsomhet og hukommelse for smertefulle opplevelser grunnet et umodent nervesystem. Tilsvarende tall ble funnet i forhold til myten om at til studien. Kunnskapsnivået til de 23,1 prosentene som ikke besvarte spørreundersøkelsen, er ukjent. Funnene går i samme med PNKAS (14-16). Likevel er de ikke nødvendigvis representative for alle sykepleiere $\mathrm{i}$ Norge, i og med at deltakerne er rekruttert fra én høyskole og tre sykehus innenfor én helseregion. At utvalget er rekruttert fra avdelinger som hyppig benytter opioider, kan ha påvirket resultatet. Respondentene i denne studien kan ha flere riktige svar enn om utvalget hadde blitt rekruttert fra alle typer barneavdelinger.

\section{KONKLUSJON}

Sykepleierne og spesialsykepleierne som deltok i studien har god kunnskap innen viktige områder innenfor feltet barn og smerter. Myter om at spedbarn ikke tåler opiater og har nedsatt smertefølsomhet, vises i liten grad i studien. Deltakerne mener videre at barn ikke skal oppmuntres til å tåle smerte, og at smerte retning som tilsvarende studier må behandles individuelt. Det eksisterer likevel et gap mellom hva sykepleierne og spesialsykepleierne har kunnskaper om og hvordan smertevurdering og behandling synliggjøres $\mathrm{i}$ «handling», når de stilles overfor to pasienthistorier. Denne manglende handlingskompetansen i kombinasjon med engstelse for respirasjonsdepresjon og medikamentavhengighet som bivirkning til opioidebehandling, samt mangelfull kunnskap om enkelte medikamenter, synliggjør områder for forbedring.

Det er av interesse å gjennomføre tilsvarende studier i andre deler av landet. Videre er det nødvendig å forske videre på hvilke faktorer som må til for å redusere gapet mellom teoretisk kunnskap og praktisk handling. Utdanning og tilrettelagt undervisning basert på kunnskapsmanglene er viktig. Det er også nødvendig å ha et fokus på de holdninger sykepleiere viser.

\section{Implikasjoner for praksis}

Ved at PNKAS har blitt validert og nå er tilgjengelig på norsk kan kartlegging av sykepleieres kunnskaper om og holdninger til smerter hos barn gjennomføres både lokalt og nasjonalt. Kun kartlegging er ikke tilfredsstillende, men gir en mulighet til å identifisere områder for forbedring (22). Undervisning og handlingsplaner bør justeres på bakgrunn av svarene, slik at kvaliteten på den smertelindringen som gis til barn ved norske barneavdelinger kan forbedres.

Takk til Norsk Sykepleierforbund, Norsk Barnesykepleierforbund og Norsk Barnesmerteforening som har gitt stipend til giennomforingen av prosjektet, samt ledere og deltakere som giorde studien mulig. 


\section{REFERANSER}

1. Kortesluoma RL, Nikkonen M, Serlo W. «You must have to make the pain go away»-Children's experiences of pain management. Pain Management Nursing 2008; 9: 143-9.

2. Schechter NL, Berde CB \& Yaster $M$. Pain in infants, children and adolescents. An overview (2nd) Phildadelphia: Lippincott Williams \& Wilkins 2003: 3-18

3. Liossi C. International Association for the study of pain (IASP). Pshycological interventions for acute and chronic pain in children. Pain Clinical Updates 2006; 14: 1-4.

4. Finley GA, Franch LS, Grunau RE, von Baeyer CL, Carr DB. International Association for the study of pain (IASP). Why childrens pain matters. Pain Clinical Updates 2005; 13: 1-6.

5. Karling $M$, Renström $M$, Ljungman G. Acute and postoperative pain in children; A Swedish nationwide survey. Acta Pædiatr 2002; 91: 660-6.

6. Bertilsson S., Sjöström B. Bedömning av smärta hos barn - en review. Vård i Norden 2005; 25: 13-18.

7. Ellis JA, O'Connor BV, Cappelli M, Goodman JT, Blouin R, Reid CW. Pain in hospitalized pediatric patient; How are we going? The Clinical Journal of Pain 2002; 18: 262-9.

8. Zempsky WT, Cravero JP, \& the Comittee on Pediatric Emergency Medicine and Section and Anesthesiology and Pain Medicine. American Academy of Pediatrics. Relief of Pain and Anxiety in Pediatric patients in emergency medical systems. Pediatrics 2004; 114: 1348-56.

9. American Academy of Pediatrics and American Pain Society. Committee on Psychososial Aspects of Child and Family Health and American Pain Society Task Force on Pain in Infants, Children and Adolescents. A position statement from the American Academy of Pediatrics. The Assessment and Management of Acute Pain in Infants, Children \& Adolescents. Pediatrics 2001; 108: 793-7.

10. Stinson J, Yamada J, Dickson A, Lamba J, Stevens B. Review of systematic reviews on acute procedural pain in children in the hospital setting. Pain Research \& Management 2008; 13: 51-7. 11. NSF. Yrkesetiske retningslinjer for sykepleiere (2007).

12. McGrath PA. Children - not simply «Little Adults». Fra Merskey H, Loesner JD, Dubner R. (edt) The Paths of Pain. IASP Press Seattle 2005: 433-46.

13. Twycross, A. Managing pain in children; where to from here? Journal of Clinical Nursing, 2010 (19): 2090-9.

14. Broome ME og Huth MM. Nursing Management of the Child in Pain. Schechter NL, Berde CB \& Yaster
M. Pain in infants, children and adolescents. (2 nd) Phildadelphia: Lippincott Williams \& Wilkins 2003: 417-33. 15. Rieman, MT, Gordon M. Pain management Competency Evidenced By a Survey of Pediatric Nurses' Knowledge and Attitudes. Pediatric Nursing, 2007; 33: 307-13.

16. Manworren R. Pediatric nurses knowledge and attitudes survey regarding pain. Pediatric Nursing, 2000; 26 : 610-14.

17. Vincent CVH. Nurses' Knowledge, Attitudes and Practices regarding childrens pain. The American Journal of Maternal Child Nursing 2005; 30: 177 $-83$

18. Salanterä S, Lauri S, Salmi TT, Helenius H. Nurses' Knowledge about Pharmacological and non pharmacological Pain Management in Children. Journal of Pain and Symptom Management 1999; 18: 289-99.

19. Enskär K, Ljusegren G, Berglund G, Eaton N, Harding R, Mokoena J, Chauke M, Moleki M. Attitudes to and knowledge about pan management of nurses working with children with canser: A comparative study between UK, South Africa and Sweden. Journal of research in Nursing 2007; 12: 501-15.

20. Salanterä S, Lauri S, Salmi T, Aantaa R. Nursing activities and outcomes of care in the assessment, management and documentation of children's pain. Journal of Paediatric Nursing 1999; 14: 408-15.

21. Andersen RD, Greve-Isdahl $M_{\text {, }}$ Meberg A, Jylli L. Oppfatninger om kunnskap og barrierer i smertebehandling av nyfødte. Vård i Norden, 2007; 83: 22-6.

22. Manworren R. Development and Testing of the Pediatric Nurses' Knowledge and Attitudes Survey Regarding Pain. Pediatric Nursing 2001; 27: 151-8. 23. McCaffery, M. Nursing practice theories related to cognition, bodily pain, and man-environment interactions. Los Angeles: UCLA Students Store 1968: 95. 24. Beaton DE, Bombardier C, Guillemin F, Ferraz, MB. Guidelines for the process of cross-cultural adaptation of self-report measures. Spine, 2000; 25 : 3186-91.

25. Koller M, Aaronsen NK, Blazeby J, Bottomley A, Dewolf L, Fayers P. Translation procedures for standardised quality of life questionnaires: The European Organisation for Research and Treatment of Cancer (EORTC) approach. European Journal of Cancer, 43, 2007: 1810-20.

26. Hovde KR, Granheim TH, Christophersen KA, Dihle A. The Norwegian Version of the Pediatric Nurses' Knowledge and Attitudes Survey Regarding Pain: Reliability and Validity. Akseptert for publikasjon 31.05.2011 i tidsskriftet
Pediatric Nursing

27. Sykepleiernes Samarbeid i Norden. Etiske retningslinjer for sykepleieforskning i Norden, 2003.

28. Kirkevold M. Vitenskap for praksis. Kap 2 Personlig kompetanse - en forutsetning for kunnskapsanvendelse s. 28 48. Oslo: Gyldendal Norsk Forlag 2002. 29. Lovdata. Lov om helsepersonell. 2. juli 1999; nr.4. (Helsepersonelloven). Tilgjengelig fra http://www.lovdata.no/ all/tl-19990702-064-008.html.

30. Manworren R. Ask the expert. It's time to relieve children's pain. Journal for specialists in Pediatric Nursing 2007; 12: 196-8.

31. Jacob E, Puntillo KA. Pain in hospitalized children: Pediatric nurses beliefs and practices. Journal of Pediatric Nursing 1999; 14: 379-91.

32. Dihle A, Bjølseth B, Helseth S. The gap between saying and doing in postoperative pain management. Journal of Clinical Nursing 2006; 15: 469-79.

33. McClain BC, \& Kain ZN. Procedural Pain in Neonates: The New Millenium. Pediatrics 2005: 115: 1073-6.

34. Franck, LS. Some Pain, Some Gain: Perfections on the past Two Decades of Neonatal Pain Research and Treatment. Neonatal Network; 2002; 21: 37-42.

35. Anand KJS, Aaranda JV, Berde CB. Summary proceedings from the neonate pain control group. Pediatrics; 2006; 117: 9-22.

36. Mountcastle K. An ounce of Prevention: Decreasing Painful Interventions in the NICU. Neonatal Network; 2010; 29: $353-8$

Les kommentaren på side 339 》> 